\title{
Systematic study of synergistic and antagonistic effects on adsorption of tetracycline and copper onto a chitosan
}

\author{
Jin Kang ${ }^{\text {a,b }}$, Huijuan Liu ${ }^{\text {a,* }}$, Yu-Ming Zheng ${ }^{c}$, Jiuhui Qu ${ }^{a}$, J. Paul Chen ${ }^{\text {c,* }}$ \\ a State Key Laboratory of Environmental Aquatic Chemistry, Research Center for Eco-Environmental Sciences, Chinese Academy of Sciences, \\ 18, Shuangqing Road, Beijing 100085, China \\ ${ }^{\mathrm{b}}$ Graduate University of Chinese Academy of Sciences, Beijing 100039, China \\ ${ }^{\mathrm{c}}$ Division of Environmental Science and Engineering, National University of Singapore, 10 Kent Ridge Crescent, Singapore
}

\section{A R T I C L E I N F O}

\section{Article history:}

Received 28 July 2009

Accepted 20 November 2009

Available online 26 November 2009

\section{Keywords:}

Adsorption

Copper

Tetracycline

Chitosan

XPS

FTIR

\begin{abstract}
A B S T R A C T
Sorption of tetracycline and copper onto chitosan is systematically investigated in this study. The sorption of tetracycline and copper occurs rapidly in the first few hours and $90 \%$ of completed uptake occurs in the first 11-12 and $6 \mathrm{~h}$, respectively. The sorption equilibrium of both contaminants is established in $24 \mathrm{~h}$. The solution pH largely affects the sorption of both contaminants. The tetracycline uptake increases as $\mathrm{pH}$ is increased from 2.8 to 5.6 , and 2.5 to 7 in the absence and the presence of copper, respectively. The presence of copper significantly improves the tetracycline adsorption likely due to the formation of cationic bridging of copper between tetracycline and chitosan. The maximum adsorption capacity and the

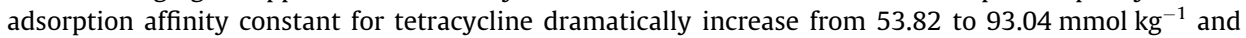
from 1.22 to $10.20 \mathrm{~L} \mathrm{mmol}^{-1}$ as the copper concentration is increased from 0 to $0.5 \mathrm{mmol} \mathrm{L}^{-1}$. The uptake of copper increases with an increase in $\mathrm{pH}$ from around 3.5-6.0 in the absence and the presence of tetracycline. The presence of tetracycline decreases the copper adsorption, which may be ascribed to the competition of tetracycline with copper ions for the adsorption sites at the chitosan surface. The adsorption isothermal data of both tetracycline and copper are fit well by the Langmuir equation. The maximum adsorption capacity and adsorption affinity constant of copper ions decrease from 1856.06 to $1486.20 \mathrm{mmol} \mathrm{kg}^{-1}$ and from 1.80 to $1.68 \mathrm{~L} \mathrm{mmol}^{-1}$ in the absence and the presence of tetracycline. FTIR and XPS studies reveal that amino, hydroxyl, and ether groups in the chitosan are involved in the adsorption of tetracycline and copper.
\end{abstract}

(c) 2009 Elsevier Inc. All rights reserved.

\section{Introduction}

Tetracycline (TC), an antibiotic, has been widely used as feed additive in the world to treat diseases and thus improve the growth rate of animals. Similar to other antibiotics, tetracycline is poorly adsorbed in the digestive tract of animals. As a result, $50-80 \%$ of tetracyclines are in animal wastes through excretion [1].

Copper as an important heavy metal has been used in many industrial operations such as semiconductor, metal plating/coating, and agricultural industries. As its salt is frequently used in animal feed as a growth promoter, its concentration in some animal wastes is high. Nicholson et al. [2] found that swine feeds and pig manures contained $18-217 \mathrm{mg}^{-C u ~ k g}{ }^{-1}$, and $360 \mathrm{mg}-\mathrm{Cu} \mathrm{kg}{ }^{-1}$ (dry weight based), respectively.

The application of animal wastes containing tetracyclines and copper for soil improvement causes contamination of tetracyclines

\footnotetext{
* Corresponding authors. Fax: +86 1062849160.

E-mail addresses: hjliu@rcees.ac.cn (H. Liu), jchen.enve97@gtalumni.org, paulchen@nus.edu.sg (J.P. Chen).
}

and copper in our aquatic environment. Discharge of industrial wastewater containing both contaminants can cause the bio-accumulation in our food chain. Tetracyclines and copper were recently found in surface water and groundwater [3-7]. The simultaneous presence of both has significantly negative environmental impacts. Kong et al. [8] reported that the coexistence of oxytetracycline and $\mathrm{Cu}$ (II) decreased Shannon's diversity index, a parameter commonly used to characterize species diversity in a community, compared with the situation when only one of the contaminants is present.

Some research was conducted recently on the interaction between tetracycline and copper. Jia et al. [9] studied the simultaneous sorption of tetracycline and copper on two soils. They found that the sorption strongly depended on soil characteristics and solution $\mathrm{pH}$. The presence of copper increased the adsorption of tetracycline at $\mathrm{pH}>4.7$, while the presence of tetracycline enhanced copper adsorption at $\mathrm{pH}<5.0$. Wang et al. studied the sorption on montmorillonite [10]. The presence of tetracycline increased the $\mathrm{Cu}$ adsorption at $\mathrm{pH}<6.5$. The tetracycline adsorption increased in the presence of $\mathrm{Cu}(\mathrm{II})$. Both studies, however, focused on the sorption behavior of tetracycline and copper on the 
metal oxide-based soil. Simultaneous uptake of tetracycline and copper ions by biosorbents has seldom been studied.

Chitosan is produced by partial deacetylation of chitin, which is the second most abundant biopolymer in the nature. It is a costeffective biosorbent for treating wastewater containing heavy metal and organic contaminants [11-13]. A series of studies revealed that chitosan had a higher adsorptive capacity for copper $[14,15]$. Few studies have been reported on the adsorption of tetracycline. As tetracycline has electron-donor groups that can form strong coordination bonds with copper [10], the adsorption of both contaminants may be affected. No study, however, has been reported in the literatures on simultaneous adsorption of both onto chitosan.

The main objective of this study was to systematically investigate the adsorption of tetracycline and copper on a chitosan, so that the interactions of the functional groups on the chitosan with both contaminants could be better understood. A series of sorption experiments was conducted to determine the sorption properties. Fourier transform infrared spectroscopy (FTIR) and X-ray photoelectron spectroscopy (XPS) were employed to elucidate the adsorption mechanisms.

\section{Materials and methods}

\subsection{Materials}

The chitosan (powder) was purchased from Sinopharm Chemical Reagent Co., Ltd., Shanghai. It had a deacetylation degree of about $90 \%$ and its viscosity was below 800 cps. Tetracycline (96\% purity) was obtained from Beijing Jing Ke Hong Da Biotechnology Co., Ltd., and used without further purification. The main physicochemical properties of tetracycline include molar mass of $444.43 \mathrm{~g} \mathrm{~mol}^{-1}$, aqueous solubility of $0.52-117 \mathrm{mmol} \mathrm{L}^{-1}$, and $\log K_{\text {ow }}$ of -1.97 to -0.47 [9]. Such chemicals as cupric sulfate pentahydrate, sodium hydroxide, and sulfuric acid were of analytical grade. Deionized water was used for all experiments.

\subsection{Determination of basic properties of chitosan}

As the raw chitosan used in our studies was not well reported in the literatures, its solubility during the sorption was a concern. We first conducted an experiment on the solubility as a function of $\mathrm{pH}$. In the experiment, a series of water solutions with sodium sulfate concentration of $0.01 \mathrm{~mol} \mathrm{~L}^{-1}$ was first prepared; the $\mathrm{pH}$ of each solution was adjusted, ranging from 2 to 9 . The chitosan with a dosage of $5 \mathrm{~g} \mathrm{~L}^{-1}$ was then added into the solution. The contact time was controlled at $24 \mathrm{~h}$. The organics leaching (total organic carbon, TOC) was determined by the TN/TC multi N/C 3000 Analyzer (Analytik Jena AG, German). The solution pH was measured by an Orion Model 720 pH electrode (Orion Research, Boston, MA, USA).

The particle size of the chitosan was determined by a laser particle size analyzer (Masterizer 2000, Malvern Co., UK). A NOVA 1200 BET Analyzer (Quantachrome, USA) was used to determine the specific surface area of the chitosan with $\mathrm{N}_{2}$ as the adsorbate at a low operating temperature. Prior to the analysis, the sample was degassed overnight at $50^{\circ} \mathrm{C}$. The specific surface area was calculated by the Brunauer-Emmett-Teller (BET) equation.

The point of zero charge (PZC) of the chitosan was measured. The amount of $0.025 \mathrm{~g}$ chitosan was added into a $25-\mathrm{mL} \mathrm{Na}_{2} \mathrm{SO}_{4}$ solution $\left(0.01 \mathrm{~mol} \mathrm{~L}^{-1}\right)$. The initial $\mathrm{pH}\left(\mathrm{pH}_{i}\right)$ ranging from 2 to 12 was adjusted by adding $\mathrm{H}_{2} \mathrm{SO}_{4}$ or $\mathrm{NaOH}$ solution. The mixtures with varied initial $\mathrm{pH}$ values $\left(\mathrm{pH}_{i}\right)$ values were shaken for $48 \mathrm{~h}$ to allow it to reach the equilibrium. The final $\mathrm{pH}\left(\mathrm{pH}_{f}\right)$ versus $\mathrm{pH}_{i}$ was plotted, by which the PZC was determined.

\subsection{Adsorption kinetics study}

In the kinetic experiments, a $0.1 \mathrm{mmol} \mathrm{L}^{-1}$ tetracycline solution was prepared. The sorbent was then added into the solution with a dosage of $2 \mathrm{~g} \mathrm{~L}^{-1}$. The mixed solution was shaken with a speed of $150 \mathrm{rpm}$ at $25 \pm 1{ }^{\circ} \mathrm{C}$. The samples were collected at appropriate time intervals and filtrated. The tetracycline concentrations were determined by a UV/Vis spectroscopy (U-3010, HITACHI Co., Japan) at a wavelength of $360 \mathrm{~nm}$ [16].

The uptake kinetics of simultaneous adsorption of tetracycline and copper was studied. In the experiment, a solution with $0.13 \mathrm{mmol} \mathrm{L}^{-1}$ tetracycline and $0.4 \mathrm{mmol} \mathrm{L}^{-1} \mathrm{Cu}$ was prepared. Then $2 \mathrm{~g} \mathrm{~L}^{-1}$ sorbent was added into the solution. The mixed solution was shaken with a speed of $150 \mathrm{rpm}$ at $25 \pm 1^{\circ} \mathrm{C}$. The samples were collected, acidified, and filtered through a $0.45-\mu \mathrm{m}$ membrane filter. Copper and tetracycline concentrations in the solution were determined by an inductively coupled plasma optical emission spectrometer (ICP-OES) (Elan 5000, Perkin Elmer, USA) and a $\mathrm{UV} / \mathrm{Vis}$ spectroscopy, respectively.

\subsection{Adsorption equilibrium study}

All experiments were conducted in 50-mL polypropylene tubes at $25 \pm 1{ }^{\circ} \mathrm{C}$. The results from the kinetic experiments showed that the adsorption equilibrium was established within $24 \mathrm{~h}$. Thus, all the adsorption equilibrium experiments were conducted with an equilibrium time of $24 \mathrm{~h}$.

\subsection{1. $p H$ effect study}

Study of the effect of $\mathrm{pH}$ on tetracycline adsorption on chitosan in the absence or the presence of copper ions was conducted as follows. First, three sets of $25 \mathrm{~mL}$ solutions were prepared. Two sets of the solutions contained $\mathrm{Na}_{2} \mathrm{SO}_{4}$ concentration of $0.01 \mathrm{~mol} \mathrm{~L}^{-1}$ (as ionic strength background), tetracycline concentration of $0.1 \mathrm{mmol} \mathrm{L}^{-1}$, and copper concentration of 0.25 or $0.5 \mathrm{mmol} \mathrm{L}^{-1}$. Another set contained $\mathrm{Na}_{2} \mathrm{SO}_{4}$ concentration of $0.01 \mathrm{~mol} \mathrm{~L}^{-1}$ and tetracycline concentration of $0.1 \mathrm{mmol} \mathrm{L}^{-1} \cdot \mathrm{H}_{2} \mathrm{SO}_{4}$ or $\mathrm{NaOH}$ was used to adjust the solution $\mathrm{pH}$ to the desired value. Then $0.1 \mathrm{~g}$ chitosan was added into the solutions, and the mixtures were shaken with a speed of $150 \mathrm{rpm}$ for $24 \mathrm{~h}$. Finally, the concentrations of tetracycline and copper were analyzed.

Study of the effect of $\mathrm{pH}$ on copper adsorption in the absence or the presence of tetracycline was conducted in a similar way as noted above. Two sets of $25-\mathrm{mL}$ solutions were prepared. One set contained $\mathrm{Na}_{2} \mathrm{SO}_{4}$ concentration of $0.01 \mathrm{~mol} \mathrm{~L}^{-1}$, copper concentration of $0.22 \mathrm{mmol} \mathrm{L}^{-1}$, and tetracycline concentration of $0.1 \mathrm{mmol} \mathrm{L}{ }^{-1}$. Another set contained $\mathrm{Na}_{2} \mathrm{SO}_{4}$ concentration of $0.01 \mathrm{mmol} \mathrm{L}^{-1}$, and copper concentration of $0.22 \mathrm{mmol} \mathrm{L}^{-1}$. The $\mathrm{pH}$ was adjusted. Then $0.025 \mathrm{~g}$ chitosan was added, the mixtures were shaken with a speed of $150 \mathrm{rpm}$ for $24 \mathrm{~h}$, and the samples were taken. Finally, the concentrations of tetracycline and copper were analyzed accordingly.

\subsubsection{Adsorption isotherm study}

Adsorption isotherm experiments of tetracycline on chitosan in the absence or the presence of copper were performed. A series of 25-mL tetracycline solutions with different concentrations (0-1.06 mmol L ${ }^{-1}$ ) first were prepared; the $\mathrm{Na}_{2} \mathrm{SO}_{4}$ and copper concentrations were fixed at $0.01 \mathrm{~mol} \mathrm{~L}^{-1}$ and $0,0.25$, or $0.5 \mathrm{mmol} \mathrm{L}^{-1}$, respectively. The solution $\mathrm{pH}$ was adjusted with $\mathrm{H}_{2} \mathrm{SO}_{4}$ or $\mathrm{NaOH}$. Then $0.1 \mathrm{~g}$ chitosan was added, and the mixtures were shaken with a speed of $150 \mathrm{rpm}$ for $24 \mathrm{~h}$. The samples were taken and analyzed accordingly.

The experiments of adsorption isotherms of copper on chitosan in the absence or the presence of tetracycline were conducted by a procedure similar to that for adsorption isotherms of tetracycline. 


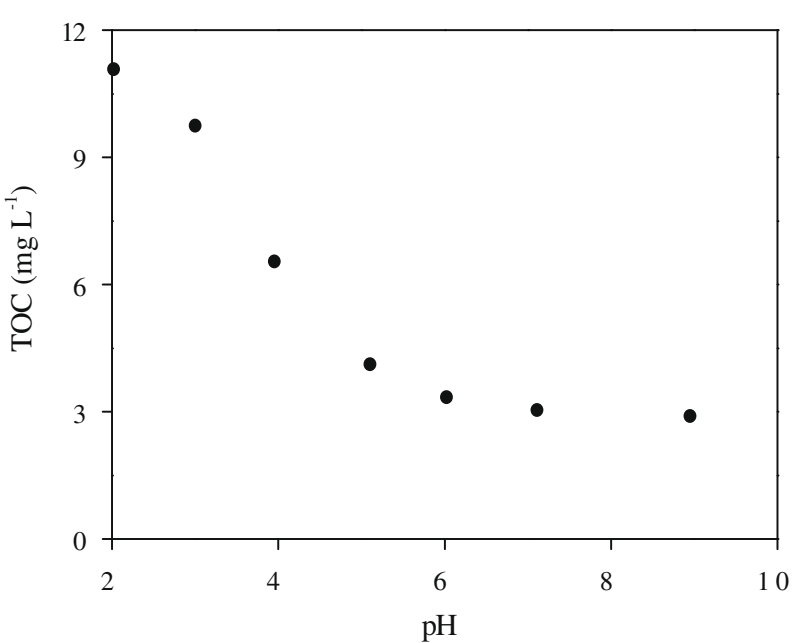

Fig. 1. Effect of $\mathrm{pH}$ on organics leaching from chitosan. Experimental conditions: $m=5 \mathrm{~g} \mathrm{~L}^{-1},\left[\mathrm{Na}_{2} \mathrm{SO}_{4}\right]=0.01 \mathrm{~mol} \mathrm{~L}^{-1}$, contact time $=24 \mathrm{~h}$.

The concentrations of copper ranged from 0 to $2.0 \mathrm{mmol} \mathrm{L}^{-1}$, and the tetracycline concentration was 0 or $0.1 \mathrm{mmol} \mathrm{L}^{-1}$. The dosage of chitosan was $1 \mathrm{~g} \mathrm{~L}^{-1}$.

\subsection{FTIR and XPS studies}

The FTIR was used to determine the vibration frequency changes in the functional groups in the virgin and tetracycline/ $\mathrm{Cu}$-loaded chitosan. Each sample was mixed with pure potassium bromide which acts as background at an approximate mass ratio of $1: 100$ (sample: $\mathrm{KBr}$ ) and then ground using an agate mortar. The resulting mixture was pressed at 10 tons for $5 \mathrm{~min}$ to form a pellet. The pellet was characterized using a Nicolet 5700 FTIR spectrometer (Thermo, USA). Thirty-two scans were collected and coadded, and $2 \mathrm{~cm}^{-1}$ resolution was applied in recording the spectra. The background obtained from scan of pure $\mathrm{KBr}$ was automatically subtracted from the sample spectra. All the spectra were recorded and plotted in the same scale on the absorbance axis.

The chemical analysis on the surfaces of sorbents was conducted by XPS (Kratos AXIS Ultra, UK), with monochromatized $\mathrm{AlK \alpha}$ X-ray source $(1486.7 \mathrm{eV})$ working at $150 \mathrm{~W}, 15 \mathrm{kV}$, and $10 \mathrm{~mA}$ and base pressure of $3 \times 10^{-8}$ Torr in the analytical chamber. For wide-scan spectra, an energy range of $0-1100 \mathrm{eV}$ was used with pass energy of $160 \mathrm{eV}$. The high-resolution scans were conducted according to the peak being examined with pass energy of $40 \mathrm{eV}$. The XPS results were collected in binding energy forms and fit using the software of Vision (PR2.1.3) and CasaXPS (2.3.12Dev7). To compensate for the charging effect, all spectra

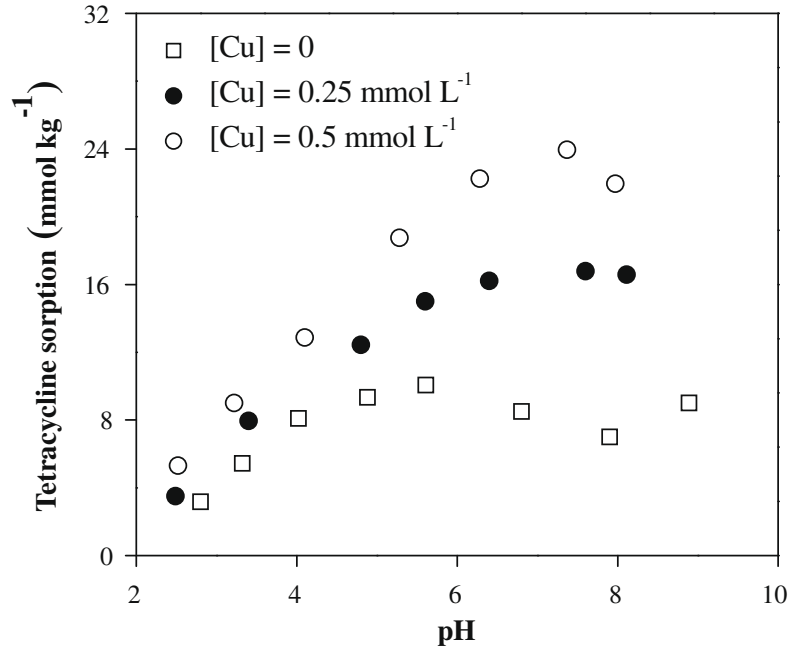

Fig. 3. pH effect on tetracycline sorption in the absence or the presence of copper ions. Experimental conditions: [tetracycline $]_{0}=0.1 \mathrm{mmol} \mathrm{L}^{-1},[\mathrm{Cu}]_{0}=0,0.25$, or $0.5 \mathrm{mmol} \mathrm{L}^{-1},\left[\mathrm{Na}_{2} \mathrm{SO}_{4}\right]=0.01 \mathrm{~mol} \mathrm{~L}^{-1}$.

were calibrated with graphitic carbon as the reference at a binding energy of $284.6 \mathrm{eV}$.

\section{Results and discussion}

\subsection{Solubility, particle size, specific area, and PZC}

As shown in Fig. 1, the organics leaching from the chitosan decreases from 10.7 to $3.1 \mathrm{mg} \mathrm{L}^{-1}$ as the solution $\mathrm{pH}$ is increased from 2 to 6 . The constant leaching is around $3 \mathrm{mg} \mathrm{L}^{-1}$ as the $\mathrm{pH}$ is further increased to 9 . The less leaching is probably due to the type of chitosan and type of anionic substance (sulfate) used in this study. The solution pH must be controlled above 6 in order that sorption of cationic contaminants can be greatly achieved (Figs. 3 and 6 ). Thus, the leaching from the chitosan at pH above 6 should not be a concern. If the $\mathrm{pH}$ must be less than 6 , a post-treatment (e.g., activated carbon adsorption and ion exchange) can be added [17].

The particle size analysis showed that the mean particle size of the chitosan was $517.9 \mu \mathrm{m}$. The specific surface area of $0.036 \mathrm{~m}^{2} \mathrm{~g}^{-1}$ was found by the BET measurement; the lower value indicates that the adsorption kinetics is controlled by the surface diffusion.

The PZC of chitosan was found to be around 8.9; this indicates that the surface of chitosan is positively charged at $\mathrm{pH}<8.9$ and negatively charged at $\mathrm{pH}>8.9$. Although the charge property does not fully determine adsorption of ionic substances, it would play an important role.
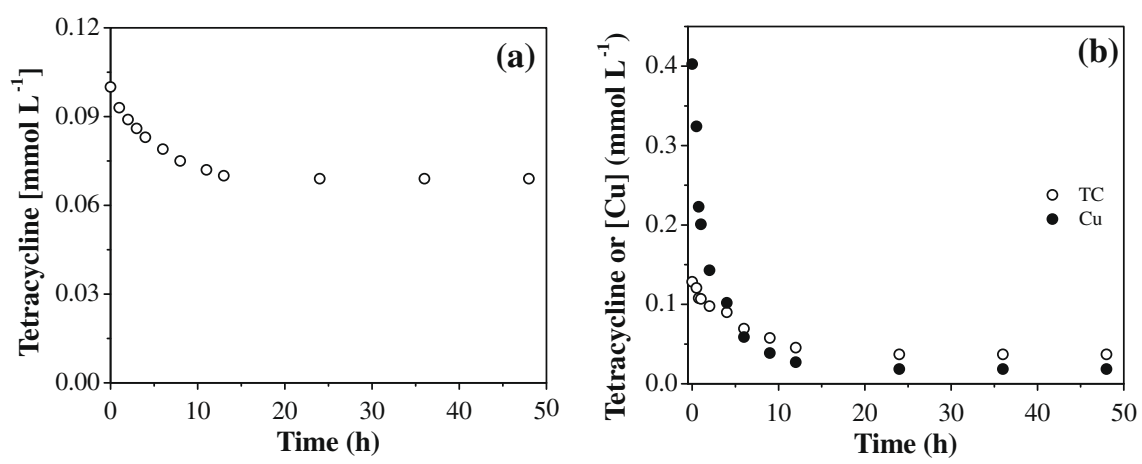

Fig. 2. Adsorption kinetics: (a) tetracycline only; (b) tetracycline and copper. Conditions: $m=2 \mathrm{~g} \mathrm{~L}^{-1}, \mathrm{pH}^{5.0}$. 


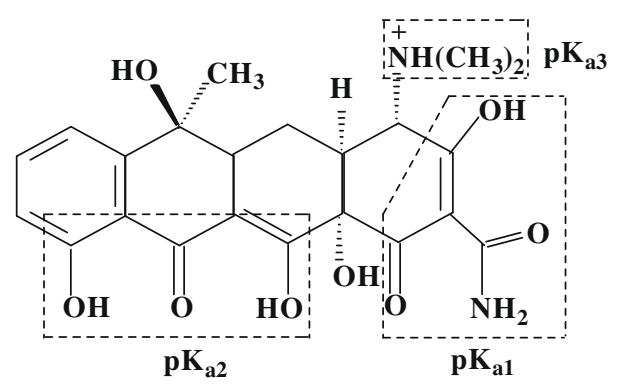

Fig. 4. Molecular structure of tetracycline $\left(\mathrm{p} K_{\mathrm{a} 1}=3.42, \mathrm{p} K_{\mathrm{a} 2}=7.59, \mathrm{p} K_{\mathrm{a} 3}=9.00\right)$.

\subsection{Adsorption kinetics}

As shown in Fig. 2, most of tetracycline and copper uptake rapidly occurs, followed by a relatively slow process. In the absence of copper, $90 \%$ of tetracycline adsorption (i.e. 905 of final adsorption) can be obtained within $11 \mathrm{~h}$ and the equilibrium is established in $24 \mathrm{~h}$, as demonstrated in Fig. 2a. In the presence of copper, 90\% of tetracycline adsorption can be achieved within $12 \mathrm{~h}$ and the complete adsorption is achieved within $24 \mathrm{~h}$; 90\% of copper adsorption occurs within $6 \mathrm{~h}$ and its equilibrium is reached within $24 \mathrm{~h}$ (Fig. 2b). The equilibrium time of $24 \mathrm{~h}$ was used in the following adsorption experiments.

The fast sorption kinetics is due to the fact that both adsorbates are cationic, which is consistent with the findings from the literatures $[18,19]$. The slightly lower tetracycline uptake rate in the presence of copper ions is likely because of the complexation between the tetracycline and the copper ions, which could increase the size of the contaminants and lead to slower internal mass transfer in the sorbent.

\subsection{Effect of $p H$}

\subsubsection{Tetracycline adsorption}

Fig. 3 shows that solution $\mathrm{pH}$ significantly affects tetracycline adsorption on chitosan. In the absence of copper ions, the adsorption of tetracycline increases when $\mathrm{pH}$ is increased from 2.8 to 5.6; it remains unchanged as the $\mathrm{pH}$ is further increased (to $\mathrm{pH} 9$ ). The $\mathrm{pH}$ effect can be associated with the $\mathrm{pH}$-dependent speciation of tetracycline and the surface properties of chitosan.

The PZC of chitosan in this study was found to be around 8.9, indicating that the surface of chitosan was positively charged over the $\mathrm{pH}$ range. As shown in Fig. 4, the tetracycline is an amphoteric molecule with multiple ionizable functional groups that exist predominantly as zwitterions in the typical $\mathrm{pH}$ in the natural aqueous environment.

Tetracycline (symbolized as $\mathrm{H}_{2} \mathrm{~L}$ ) forms a series of species as shown in Table 1 . The distribution of various species was calculated by MINEQL+ [20]. As shown in Fig. 5a, the predominate tetracycline species are $\mathrm{H}_{3} \mathrm{~L}^{+}$at $\mathrm{pH}<3.4, \mathrm{H}_{2} \mathrm{~L}$ at $3.4<\mathrm{pH}<7.6, \mathrm{HL}^{-}$at $7.6<\mathrm{pH}<9.0$, and $\mathrm{L}^{2-}$ at $\mathrm{pH}>9.0$. The tetracycline becomes less positively charged (or more negatively charged) as $\mathrm{pH}$ is increased. On the other hand, the chitosan can be treated as a weak acid (symbolized as $\mathrm{SOH}$ ) with the following reactions.

$\mathrm{SOH}=\mathrm{SO}^{-}+\mathrm{H}^{+} \quad \mathrm{pH}>\mathrm{PZC}$

$\mathrm{SOH}+\mathrm{H}^{+}=\mathrm{SOH}_{2}^{+} \quad \mathrm{pH}<\mathrm{PZC}$

$\mathrm{SOH}+m \mathrm{H}^{+}+\mathrm{H}_{n} \mathrm{~L}^{n-2}=\mathrm{SOH}_{m+1}^{m+}-\mathrm{H}_{n} \mathrm{~L}^{n-2}$.

where $m=0,1,2$ and $m+n=2$.

As $\mathrm{pH}$ is increased, the tetracycline species would become more negative and then the value in Eq. (3) decreases (Fig. 5a). As a result, higher adsorption would occur.
Table 1

List of reactions of tetracycline and copper ions.

\begin{tabular}{rlr}
\hline No. & Reaction & \multicolumn{1}{c}{$\log k$} \\
\hline 1 & $\mathrm{H}_{3} \mathrm{~L}^{+}-\mathrm{H}^{+} \rightarrow \mathrm{H}_{2} \mathrm{~L}$ & -3.42 \\
2 & $\mathrm{H}_{3} \mathrm{~L}^{+}-2 \mathrm{H}^{+} \rightarrow \mathrm{HL}^{-}$ & -11.01 \\
3 & $\mathrm{H}_{3} \mathrm{~L}^{+}-3 \mathrm{H}^{+} \rightarrow \mathrm{L}^{2-}$ & -20.01 \\
4 & $\mathrm{H}_{3} \mathrm{~L}^{+}-\mathrm{H}^{+}+\mathrm{Cu}^{2+} \rightarrow \mathrm{Cu}\left(\mathrm{H}_{2} \mathrm{~L}\right)^{2+}$ & 0.48 \\
5 & $\mathrm{H}_{3} \mathrm{~L}^{+}-2 \mathrm{H}^{+}+\mathrm{Cu}^{2+} \rightarrow \mathrm{Cu}(\mathrm{HL})^{+}$ & -2.60 \\
6 & $\mathrm{H}_{3} \mathrm{~L}^{+}-3 \mathrm{H}^{+}+\mathrm{Cu}^{2+} \rightarrow \mathrm{CuL}$ & -8.55 \\
7 & $2 \mathrm{H}_{3} \mathrm{~L}^{+}-2 \mathrm{H}^{+}+\mathrm{Cu}^{2+} \rightarrow \mathrm{Cu}\left(\mathrm{H}_{4} \mathrm{~L}_{2}\right)^{2+}$ & 0.51 \\
8 & $2 \mathrm{H}_{3} \mathrm{~L}^{+}-3 \mathrm{H}^{+}+\mathrm{Cu}^{2+} \rightarrow \mathrm{Cu}\left(\mathrm{H}_{3} \mathrm{~L}_{2}\right)^{+}$ & -2.55 \\
9 & $2 \mathrm{H}_{3} \mathrm{~L}^{+}-4 \mathrm{H}^{+}+\mathrm{Cu}^{2+} \rightarrow \mathrm{Cu}\left(\mathrm{H}_{2} \mathrm{~L}_{2}\right)$ & -7.52 \\
10 & $2 \mathrm{H}_{3} \mathrm{~L}^{+}-5 \mathrm{H}^{+}+\mathrm{Cu}^{2+} \rightarrow \mathrm{Cu}\left(\mathrm{HL}_{2}\right)^{-}$ & -14.82 \\
\hline
\end{tabular}

The $\log K$ values for the calculation of the speciation distribution were obtained from the literature [10].
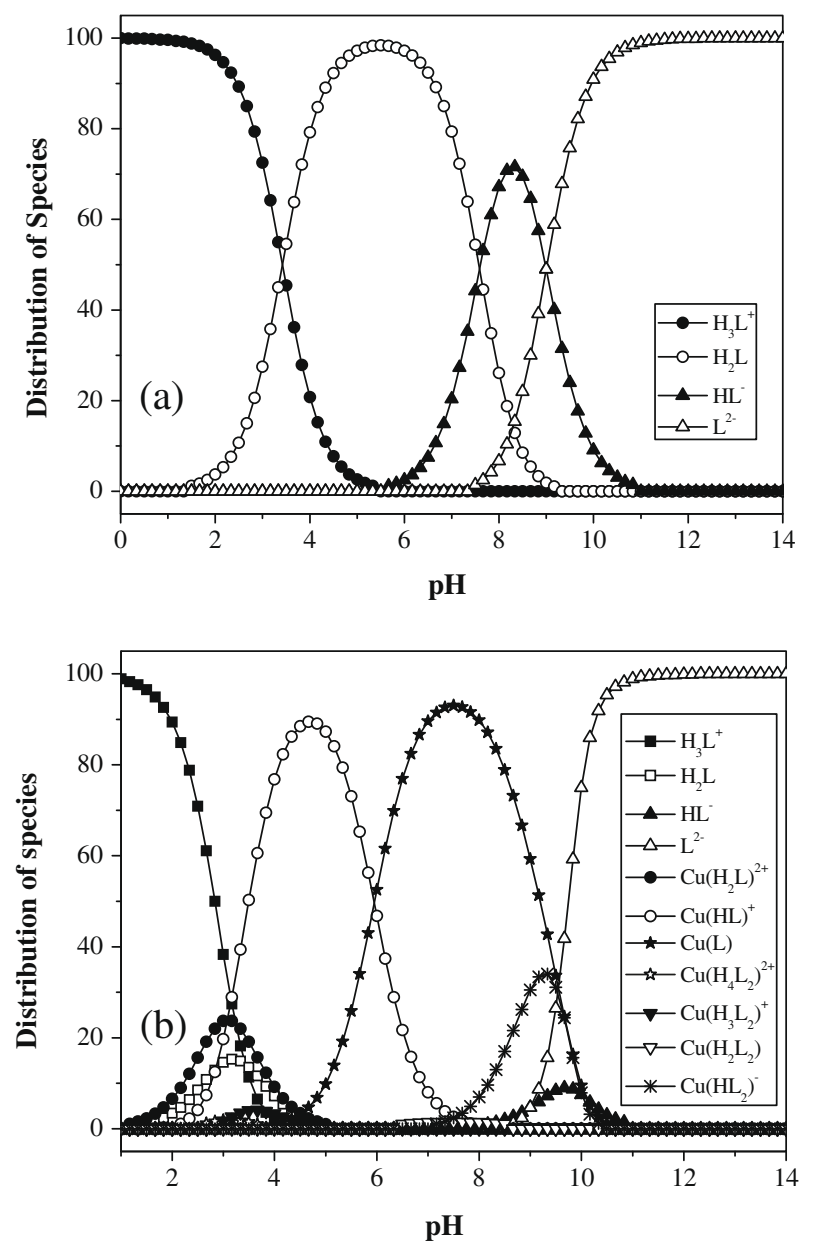

Fig. 5. Distribution of tetracycline as a function of solution $\mathrm{pH}$ : (a) tetracycline only; (b) $[\mathrm{Cu}]=0.25 \mathrm{mmol} \mathrm{L}^{-1}$ and [tetracycline $]=0.1 \mathrm{mmol} \mathrm{L}^{-1}$.

Tetracycline uptake increases as $\mathrm{pH}$ is increased from 2.5 to 7 in the presence of copper. The presence of copper greatly increases the adsorption of tetracycline as shown in Fig. 3. Copper ions can form water-soluble complexes with tetracycline as shown in Table 1. The distribution of tetracycline species in the presence of $0.1 \mathrm{mmol} \mathrm{L}^{-1}$ tetracycline and $0.25 \mathrm{mmol} \mathrm{L}^{-1}$ copper was determined by the MINIQL+.

As shown in Fig. 5b, the predominating tetracycline species in the presence of copper are $\mathrm{H}_{3} \mathrm{~L}^{+}, \mathrm{Cu}\left(\mathrm{H}_{2} \mathrm{~L}\right)^{2+}$, and $\mathrm{H}_{2} \mathrm{~L}$ at $\mathrm{pH}<3$; $\mathrm{Cu}(\mathrm{HL})^{+}, \mathrm{Cu}\left(\mathrm{H}_{2} \mathrm{~L}\right)^{2+}$, and $\mathrm{H}_{2} \mathrm{~L}$ at $3<\mathrm{pH}<5 ; \mathrm{Cu}(\mathrm{HL})^{+}$and $\mathrm{CuL}$ at $5<\mathrm{pH}<6$; and $\mathrm{CuL}$ and $\mathrm{Cu}(\mathrm{HL})^{+}$at $6<\mathrm{pH}<8$. The tetracycline spe- 


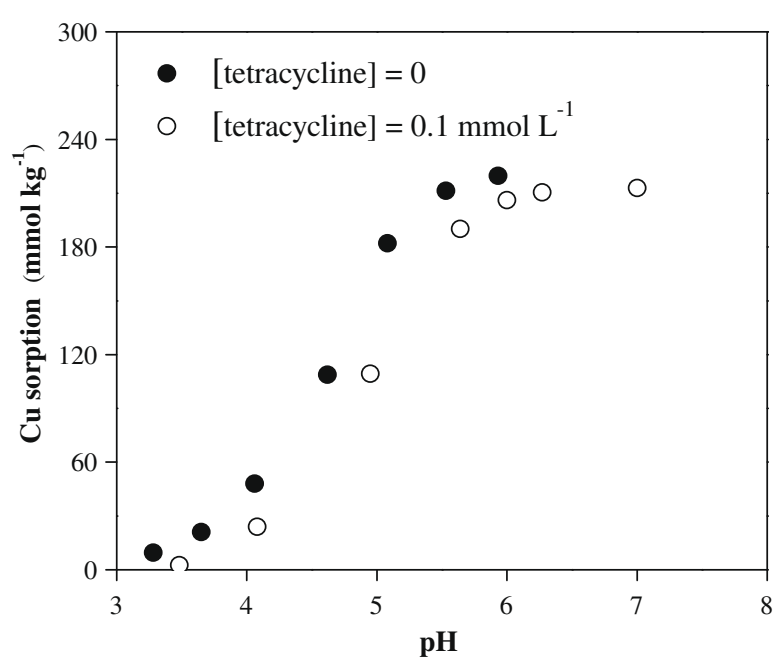

Fig. 6. $\mathrm{pH}$ effect on the adsorption of $\mathrm{Cu}$ on chitosan in the absence or the presence of TC. Experimental conditions: $[\mathrm{Cu}]_{0}=0.22 \mathrm{mmol} \mathrm{L}^{-1}$, [Tetracycline $]_{0}=0$ or $0.1 \mathrm{mmol} \mathrm{L}^{-1},\left[\mathrm{Na}_{2} \mathrm{SO}_{4}\right]=0.01 \mathrm{~mol} \mathrm{~L}^{-1}$.

cies in the presence of copper carry more positive charges than tetracycline species in the absence of copper, which should reduce the tetracycline adsorption according to the rule of electrostatic repulsion. However, Fig. 3 shows a totally different trend. This leads to a hypothesis that the copper ions act as a bridge between chitosan and tetracycline. As the copper has higher affinity to the sorbent, the tetracycline (complexed with copper) can be greatly adsorbed. Similar observations were reported on the adsorption of organic ligands in the presence of metals [21,22].

\subsubsection{Copper adsorption}

As shown in Fig. 6, the copper adsorption on chitosan increases with an increase in equilibrium $\mathrm{pH}$ from 3.3 , and reaches a maximum adsorption at $\mathrm{pH} 6.0$, which is in agreement with the findings in the literature $[17,18,23,24]$. At lower $\mathrm{pH}$, the amino groups in chitosan are easily protonated, which induces an electrostatic repulsion of copper ions. Moreover, the competition between protons and copper ions for adsorption sites decreases the adsorption capacity. As pH is increased, the functional groups become less positively charged, leading to higher copper adsorption. The sorption reaction can be described as

$\mathrm{SOH}+\mathrm{Cu}^{2+}=\mathrm{SO}-\mathrm{Cu}^{+}+\mathrm{H}^{+}$.

When tetracycline is present in the solution, the adsorption increases from 3.5 to 6.0 (Fig. 6). The presence of tetracycline, however, hinders the sorption. As shown in Table 1, the tetracycline is a strong complexing ligand for copper ions. It competes with the functional groups in the sorbent for the coppers ions, leading to less metal adsorption. Malandrino et al. studied the adsorption of heavy metals such as copper, lead, and cadmium on vermiculite [25]. The metal uptake on the clay was hindered by the presence of strong complexing agents in solution and decreased with the increasing concentrations of the ligands. Furthermore, Abollino et al. reported that EDTA and NTA dramatically reduced the adsorption of metal ions onto montmorillonite and vermiculite [26].

\subsection{Adsorption isotherms}

Adsorption isotherms of tetracycline on chitosan in the absence and the presence of copper are presented in Fig. 7. The amounts of tetracycline adsorbed on chitosan increase with an increase in tet-

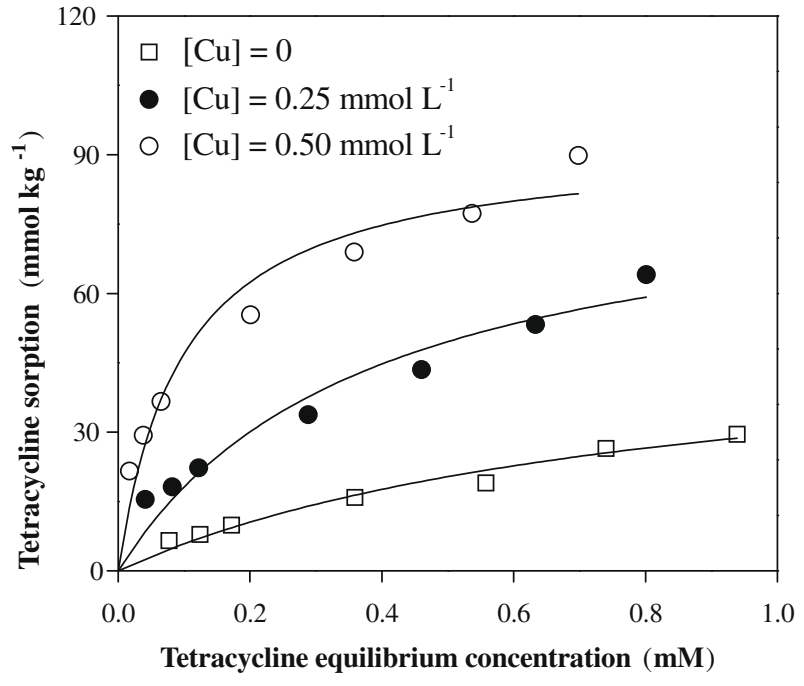

Fig. 7. Adsorption isotherms of tetracycline in the absence or the presence of $\mathrm{Cu}(\mathrm{II})$. Experimental conditions: $m=4 \mathrm{~g} \mathrm{~L}^{-1},[\mathrm{Cu}]_{0}=0,0.25$, or $0.5 \mathrm{mmol} \mathrm{L}^{-1},\left[\mathrm{Na}_{2} \mathrm{SO}_{4}\right]=$ $0.01 \mathrm{mmol} \mathrm{L}^{-1}, \mathrm{pH}$ 6.7. Points represent experimental data, while lines represent modeling results.

racycline equilibrium concentration. When copper is present in the solution, tetracycline adsorption significantly increases, which can be ascribed to the higher sorption affinity of tetracycline-Cu complexes as discussed.

Adsorption isotherms of copper in the absence and the presence of tetracycline are shown in Fig. 8. The adsorption increases with the increasing copper equilibrium concentration. The presence of tetracycline decreases the adsorption of copper on chitosan, indicating that tetracycline-copper complexes have a lower affinity to chitosan than copper alone. This result is not in agreement with that reported by Wang et al. [10]. This is due to the difference in the composition of both sorbents. In their study, montmorillonite was used as an adsorbent. The sorbent essentially consists of metal oxides (e.g., aluminum/iron oxides) and the sorption is due to the surface complexation between copper/tetracycline and the hydroxide group $(-\mathrm{OH})$ on the sorbent. The chitosan in our study, however, contains high contents of organic functional groups;

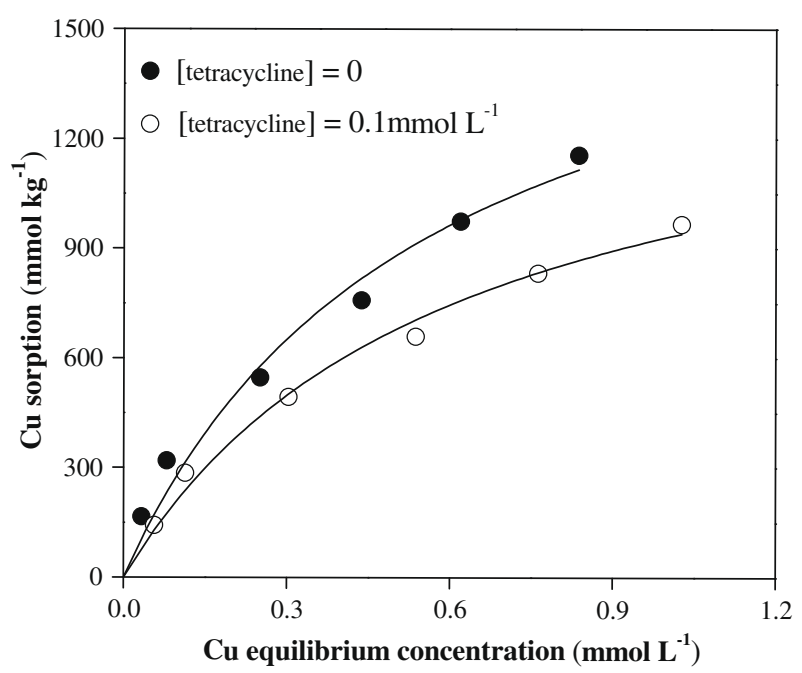

Fig. 8. Adsorption isotherms of copper in the absence or the presence of tetracycline. Experimental conditions: $m=1 \mathrm{~g} \mathrm{~L}^{-1}$, [tetracycline] $]_{0}=0$ or $0.1 \mathrm{mmol} \mathrm{L}^{-1}$, $\left[\mathrm{Na}_{2} \mathrm{SO}_{4}\right]=0.01 \mathrm{mmol} \mathrm{L}^{-1}, \mathrm{pH}=5.0$. Points represent experimental data, while lines represent modeling results. 
Table 2

Langmuir parameters for the adsorption of tetracycline and/or copper.

\begin{tabular}{llccc}
\hline & Condition & $\begin{array}{l}q_{\max } \\
\left(\mathrm{mmol} \mathrm{kg}^{-1}\right)\end{array}$ & $\begin{array}{l}b \\
\left(\mathrm{~L} \mathrm{mmol}^{-1}\right)\end{array}$ & $r^{2}$ \\
\hline Tetracycline & {$[\mathrm{Cu}]=0$} & 53.82 & 1.22 & 0.97 \\
& {$[\mathrm{Cu}]=0.25 \mathrm{mmol} \mathrm{L}^{-1}$} & 87.42 & 2.61 & 0.93 \\
& {$[\mathrm{Cu}]=0.50 \mathrm{mmol} \mathrm{L}^{-1}$} & 93.04 & 10.20 & 0.94 \\
Copper & {$[$ Tetracycline] $=0$} & 1856.06 & 1.80 & 0.97 \\
& {$[$ Tetracycline] $=$} & 1486.20 & 1.68 & 0.99 \\
& $0.1 \mathrm{mmol} \mathrm{L}^{-1}$ & & & \\
\hline
\end{tabular}

the sorption is thus due to the formation of copper/tetracycline organic complexes.

The Langmuir equation shown below is used to describe the sorption data.

$q_{e}=\frac{q_{\max } b C_{e}}{1+b C_{e}}$

where $q_{\text {max }}$ is the maximum adsorption capacity, $b$ is the adsorption affinity constant related to the binding energy of adsorption, and $q_{e}$ and $C_{e}$ are the equilibrium concentrations in the sorbent and the solution, respectively.

The calculated parameters of equation are listed in Table 2 . The equation fits the adsorption isotherms of tetracycline and copper well with higher correlation coefficients $\left(r^{2}=0.93-0.99\right)$. This indicates that the uptake of tetracycline and/or copper on chitosan is monolayer adsorption.

The values of maximum adsorption capacity $\left(q_{\max }\right)$ of copper ions are 1856.06 and $1486.20 \mathrm{mmol} \mathrm{kg}^{-1}$ in the absence and the presence of tetracycline $\left(0.1 \mathrm{mmol} \mathrm{L}^{-1}\right)$, respectively. Both show that chitosan has a higher adsorptive capacity for copper. This is consistent with the results by other biosorbents such as calcium alginate and Sargassum (few mmol per gram of calcium alginate applied) $[18,19,23]$. The slight decrease in the adsorption affinity constant (from 1.80 to $1.68 \mathrm{~L} \mathrm{mmol}^{-1}$ ) indicates the competitive effect resulting from the presence of tetracycline.

The maximum adsorption capacity of tetracycline increases from 53.82 to $93.04 \mathrm{mmol} \mathrm{kg}^{-1}$ when the copper concentration is increased from 0 to $0.5 \mathrm{mmol} \mathrm{L}^{-1}$. The adsorption affinity constant dramatically increases from 1.22 to $10.20 \mathrm{~L} \mathrm{mmol}^{-1}$. These all indicate that chitosan is a good adsorbent to treat waste streams with both tetracycline and copper.

\subsection{Fourier transform infrared spectroscopy}

FTIR spectra of virgin and adsorbate-loaded chitosan are shown in Fig. 9. The broad and strong band ranging from 3200 to $3600 \mathrm{~cm}^{-1}$ may be due to the overlapping of $-\mathrm{OH}$ and -NH stretching bands. The peak shift from 3445.7 to $3431 \mathrm{~cm}^{-1}$ is observed after the adsorption of tetracycline onto the surface of sorbent, indicating that $-\mathrm{OH}$ and $-\mathrm{NH}$ are involved in the adsorption.

The band at $1657.1 \mathrm{~cm}^{-1}$ can be assigned to the amide I, while the band at $1598.3 \mathrm{~cm}^{-1}$ can be assigned to the amide II and $\mathrm{N}-\mathrm{H}$ bending vibration in chitosan molecules. After the tetracycline adsorption, the bands at 1657.1 and $1598.3 \mathrm{~cm}^{-1}$ shift to 1632.7 and $1536.4 \mathrm{~cm}^{-1}$, respectively. The two new bands can be assigned as follows: the band at $1632.7 \mathrm{~cm}^{-1}$ is due to the amide I and antisymmetric $-\mathrm{NH}_{3}^{+}$deformation, while that at $1536.4 \mathrm{~cm}^{-1}$ indicates the amide II, $\mathrm{N}-\mathrm{H}$ bending vibration and the symmetric $-\mathrm{NH}_{3}^{+}$ deformation [27]. The change at these two bands may be attributed to the protonation of an amino group in chitosan and the interaction between tetracycline and amino group in the chitosan. In other words, the tetracycline adsorption affects all of the bands with $\mathrm{N}$ atom.

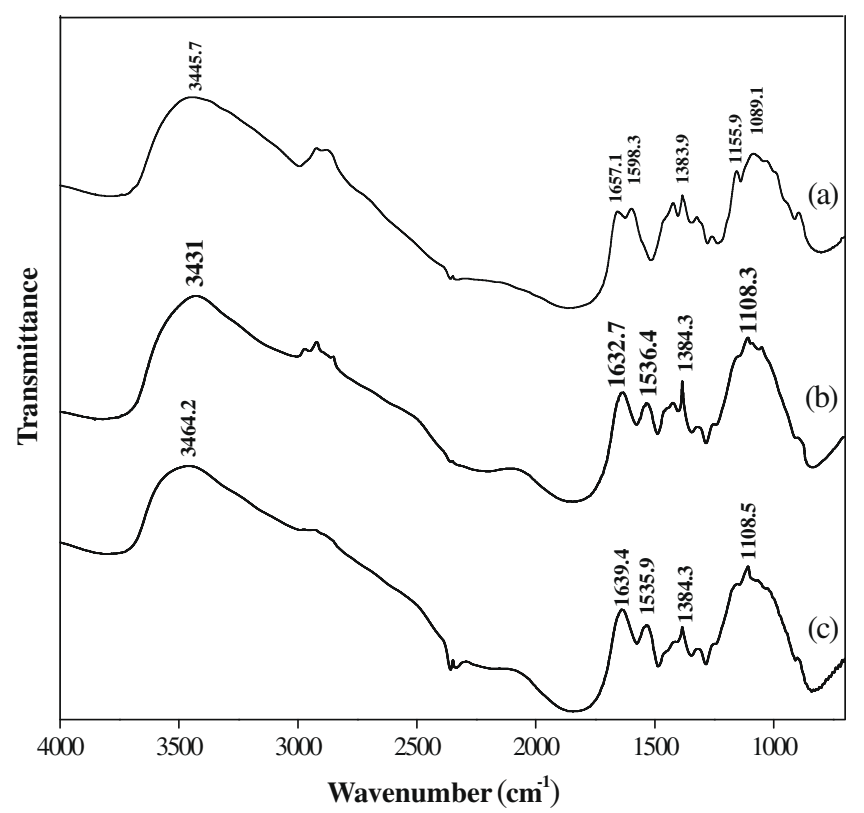

Fig. 9. FTIR spectra of: (a) virgin chitosan; (b) tetracycline-loaded chitosan; (c) Culoaded chitosan.

The $\mathrm{C}-\mathrm{O}$ stretching vibration of alcoholic hydroxyl group (1080-1120 $\mathrm{cm}^{-1}$ ) after the tetracycline adsorption has a narrower peak than the virgin sorbent. This indicates that the alcoholic hydroxyl groups are involved in the adsorption. The adsorption band at $1155.9 \mathrm{~cm}^{-1}$ due to asymmetric stretching of C-O-C is less obvious in the sorbent after the tetracycline adsorption, which could be due to the shift of alcoholic hydroxyl group at the nearby adsorbent zone $\left(1108.3 \mathrm{~cm}^{-1}\right)$ and the involvement of ether groups in the tetracycline adsorption.

Fig. 9 shows that the adsorption band at $3445.7 \mathrm{~cm}^{-1}$ in the virgin sorbent shifts to $3464.2 \mathrm{~cm}^{-1}$ after the copper adsorption, indicating the involvement of both $-\mathrm{OH}$ and $-\mathrm{NH}$ groups in the metal binding. In addition, the adsorption bands at 1657.1 and $1598.3 \mathrm{~cm}^{-1}$ shift to 1639.4 and $1535.9 \mathrm{~cm}^{-1}$ after the sorption, respectively, demonstrating the participation of amino groups in the metal sorption. The change of adsorption band assigned to the $\mathrm{C}-\mathrm{O}-\mathrm{C}$ group is similar to that after the tetracycline adsorption.

\subsection{X-ray photoelectron spectroscopy}

To further investigate the interactions among tetracycline, copper, and chitosan, XPS studies of chitosan before and after the adsorption of copper and/or tetracycline were conducted. The results of a wide scan of samples in Fig. 10 show that the major elements of chitosan are $\mathrm{C}, \mathrm{N}$, and $\mathrm{O}$. The presence of a $\mathrm{Cu}(\mathrm{II}) 2 \mathrm{p}$ peak in $\mathrm{Cu}$ - and tetracycline/Cu-loaded chitosans provides evidence of the copper adsorption onto the sorbent.

The high-resolution $C 1 \mathrm{~s}$ spectra of the chitosan before and after the adsorption shown in Fig. 11 could be deconvoluted into three individual component peaks: $284.8 \mathrm{eV}$ (C-C and/or C-H groups), $286.3-286.5 \mathrm{eV}$ (C-N and/or C-O bonds), and $287.9-288.2 \mathrm{eV}$ (O- $\mathrm{C}-\mathrm{O}$ and/or $\mathrm{C}=\mathrm{O}$ groups existing in residual chitin-like rings) [28]. The relative contents of the different groups in the absorbent were calculated and summarized in Table 3 . The relative quantity at 286.3-286.5 eV (amino, alcoholic hydroxyl, and/or ether groups) decreases after the adsorption of $\mathrm{Cu}$ and/or tetracycline, indicating the involvement of the functional groups in the adsorption of copper and tetracycline onto the chitosan. This is consistent with the 


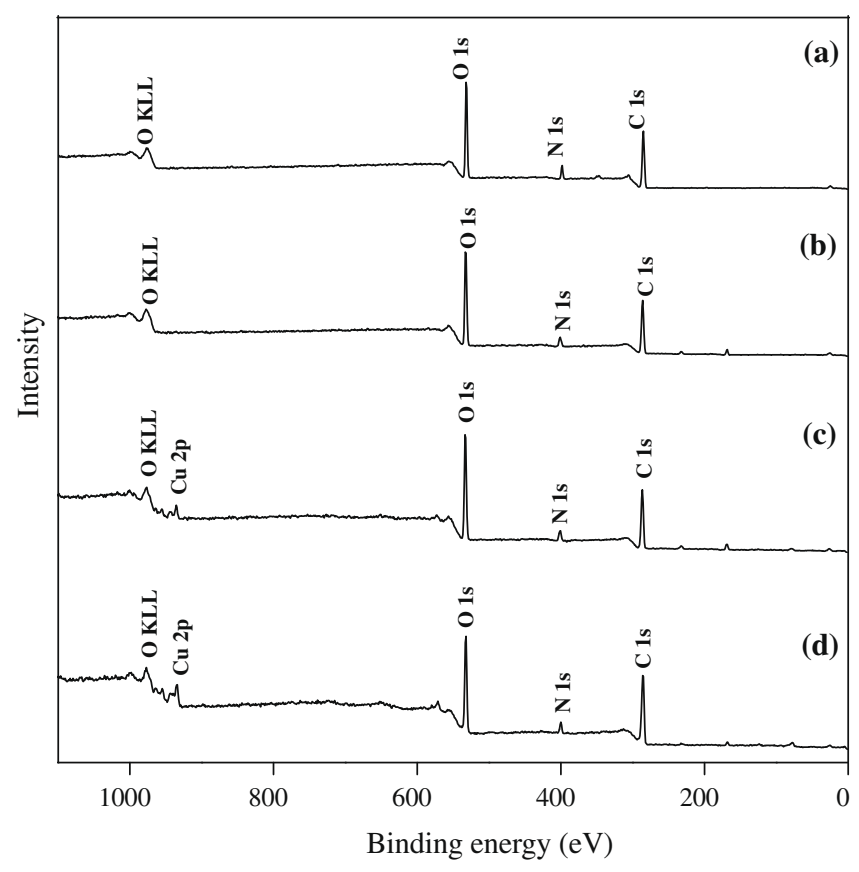

Fig. 10. XPS wide-scan spectra. (a) Virgin chitosan; (b) tetracycline-loaded chitosan; (c) Cu-loaded chitosan; (d) tetracycline/Cu-loaded chitosan.

FTIR analysis. It suggests that tetracycline and copper will compete for these functional groups in chitosan when they coexist.

The XPS spectra of $O 1 \mathrm{~s}$ in Fig. 11 can be deconvoluted into two different component peaks with binding energy of 531.2-531.7 and $532.7-532.9 \mathrm{eV}$, which can be assigned to $\mathrm{C}=\mathrm{O}$ (carbonyl) and C-O (alcohol hydroxyl and/or ether), respectively [29]. After the adsorption of copper, the peak of $531.7 \mathrm{eV}$ (in virgin sorbent) shifts to $531.2 \mathrm{eV}$ (Cu- and tetracycline/Cu-loaded chitosans). The shift of the binding energy can be attributed to the interaction of metal with oxygen. Hydroxyl and ether groups can form metal complexes with copper, in which oxygen atoms donate electrons to copper and the electron density toward the oxygen atoms in these groups decrease (the decrease in relative content of $\mathrm{C}-\mathrm{O}$ (alcohol hydroxyl and ether) after the adsorption of tetracycline and/or Cu shown in Table 3) [30]. The geometric shape of the ether group would reportedly undergo the greatest change among the three functional groups (namely hydroxyl, carboxyl, and ether) when they form the metal complexes [31]. The adjustment of geo-
Table 3

Summary of binding energy and relative content of elements in chitosan.

\begin{tabular}{|c|c|c|c|}
\hline Sample surface & $\begin{array}{l}\text { Proposed } \\
\text { components }\end{array}$ & $\begin{array}{l}\text { Binding } \\
\text { energy }(\mathrm{eV})\end{array}$ & $\begin{array}{l}\text { Relative } \\
\text { quantity }\end{array}$ \\
\hline \multicolumn{4}{|l|}{ C $1 \mathrm{~s}$ valence state } \\
\hline \multirow[t]{3}{*}{ (a) } & $\mathrm{C}-\mathrm{C}$ or $\mathrm{C}-\mathrm{H}$ & 284.8 & 0.20 \\
\hline & $\mathrm{C}-\mathrm{N}$ or $\mathrm{C}-\mathrm{O}$ or $\mathrm{C}-\mathrm{O}-\mathrm{C}$ & 286.4 & 0.65 \\
\hline & $\mathrm{C}=\mathrm{O}$ or $\mathrm{O}-\mathrm{C}-\mathrm{O}$ & 288.2 & 0.15 \\
\hline \multirow[t]{3}{*}{ (b) } & $\mathrm{C}-\mathrm{C}$ or $\mathrm{C}-\mathrm{H}$ & 284.8 & 0.34 \\
\hline & $\mathrm{C}-\mathrm{N}$ or $\mathrm{C}-\mathrm{O}$ or $\mathrm{C}-\mathrm{O}-\mathrm{C}$ & 286.3 & 0.50 \\
\hline & $\mathrm{C}=\mathrm{O}$ or $\mathrm{O}-\mathrm{C}-\mathrm{O}$ & 287.9 & 0.16 \\
\hline \multirow[t]{3}{*}{ (c) } & $\mathrm{C}-\mathrm{C}$ or $\mathrm{C}-\mathrm{H}$ & 284.8 & 0.22 \\
\hline & $\mathrm{C}-\mathrm{N}$ or $\mathrm{C}-\mathrm{O}$ or $\mathrm{C}-\mathrm{O}-\mathrm{C}$ & 286.5 & 0.62 \\
\hline & $\mathrm{C}=\mathrm{O}$ or $\mathrm{O}-\mathrm{C}-\mathrm{O}$ & 288.2 & 0.16 \\
\hline \multirow[t]{3}{*}{ (d) } & $\mathrm{C}-\mathrm{C}$ or $\mathrm{C}-\mathrm{H}$ & 284.8 & 0.46 \\
\hline & $\mathrm{C}-\mathrm{N}$ or $\mathrm{C}-\mathrm{O}$ or $\mathrm{C}-\mathrm{O}-\mathrm{C}$ & 286.5 & 0.38 \\
\hline & $\mathrm{C}=\mathrm{O}$ or $\mathrm{O}-\mathrm{C}-\mathrm{O}$ & 287.9 & 0.16 \\
\hline \multicolumn{4}{|l|}{ O $1 \mathrm{~s}$ valence state } \\
\hline \multirow[t]{2}{*}{ (a) } & $\mathrm{C}=\mathrm{O}$ & 531.7 & 0.16 \\
\hline & $\mathrm{O}-\mathrm{H}$ or $\mathrm{C}-\mathrm{O}-\mathrm{C}$ & 532.8 & 0.84 \\
\hline \multirow[t]{2}{*}{ (b) } & $\mathrm{C}=\mathrm{O}$ & 531.5 & 0.37 \\
\hline & $\mathrm{O}-\mathrm{H}$ or $\mathrm{C}-\mathrm{O}-\mathrm{C}$ & 532.7 & 0.63 \\
\hline \multirow[t]{2}{*}{ (c) } & $\mathrm{C}=\mathrm{O}$ & 531.2 & 0.20 \\
\hline & $\mathrm{O}-\mathrm{H}$ or $\mathrm{C}-\mathrm{O}-\mathrm{C}$ & 532.9 & 0.80 \\
\hline \multirow[t]{2}{*}{ (d) } & $\mathrm{C}=\mathrm{O}$ & 531.2 & 0.28 \\
\hline & $\mathrm{O}-\mathrm{H}$ or $\mathrm{C}-\mathrm{O}-\mathrm{C}$ & 532.7 & 0.72 \\
\hline \multicolumn{4}{|l|}{$N 1 s$ valence state } \\
\hline (a) & $-\mathrm{NH}$ or $-\mathrm{NH}_{2}$ & 399.5 & - \\
\hline \multirow[t]{2}{*}{ (b) } & $-\mathrm{NH}$ or $-\mathrm{NH}_{2}$ & 399.3 & 0.35 \\
\hline & $-\mathrm{NH}_{3}^{+}$ & 401.4 & 0.65 \\
\hline \multirow[t]{2}{*}{ (c) } & $-\mathrm{NH}$ or $-\mathrm{NH}_{2}$ & 400.0 & 0.71 \\
\hline & $-\mathrm{NH}_{3}^{+}$ & 401.9 & 0.29 \\
\hline \multirow[t]{2}{*}{ (d) } & $-\mathrm{NH}$ or $-\mathrm{NH}_{2}$ & 399.8 & 0.75 \\
\hline & $-\mathrm{NH}_{3}^{+}$ & 401.9 & 0.25 \\
\hline
\end{tabular}

(a) Virgin chitosan; (b) tetracycline-loaded chitosan; (c) Cu-loaded chitosan; (d) tetracycline $+\mathrm{Cu}(\mathrm{II})$ loaded chitosan.

metric shape of ether groups may be responsible for the less obvious $\mathrm{C}-\mathrm{O}-\mathrm{C}$ stretching in FTIR spectra after adsorption of tetracycline and $\mathrm{Cu}$.

The high-resolution N 1s XPS spectra of the chitosans are shown in Fig. 12. At neutral $\mathrm{pH}$, there is only one single $\mathrm{N} 1 \mathrm{~s}$ peak located at $399.5 \mathrm{eV}$ for virgin chitosan. After being exposed to $\mathrm{Cu}(\mathrm{II})$ and/or tetracycline, the chitosan exhibits two peaks: $399.3-400.0 \mathrm{eV}$ assigned to the nitrogen atoms in the forms of $-\mathrm{NH}_{2}$ and/or $-\mathrm{NH}$ groups, and 401.4-401.9 eV assigned to the protonated nitrogen $\left(-\mathrm{NH}_{3}^{+}\right)$(under acidic conditions) [28]. Under acidic conditions, the protonated chitosan is ineffective in the removal of such cations as copper ions. The copper sorption is followed by a charge
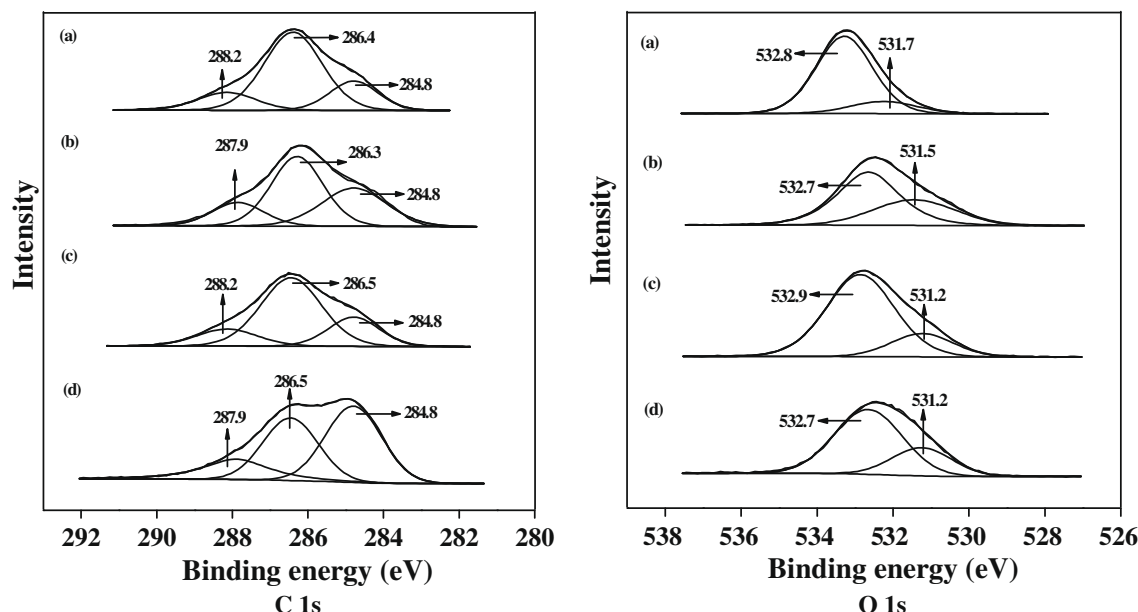

Fig. 11. XPS spectra of $C$ 1s and $O$ 1s. (a) Virgin chitosan; (b) tetracycline-loaded chitosan; (c) Cu-loaded chitosan; (d) tetracycline/Cu-loaded chitosan. 

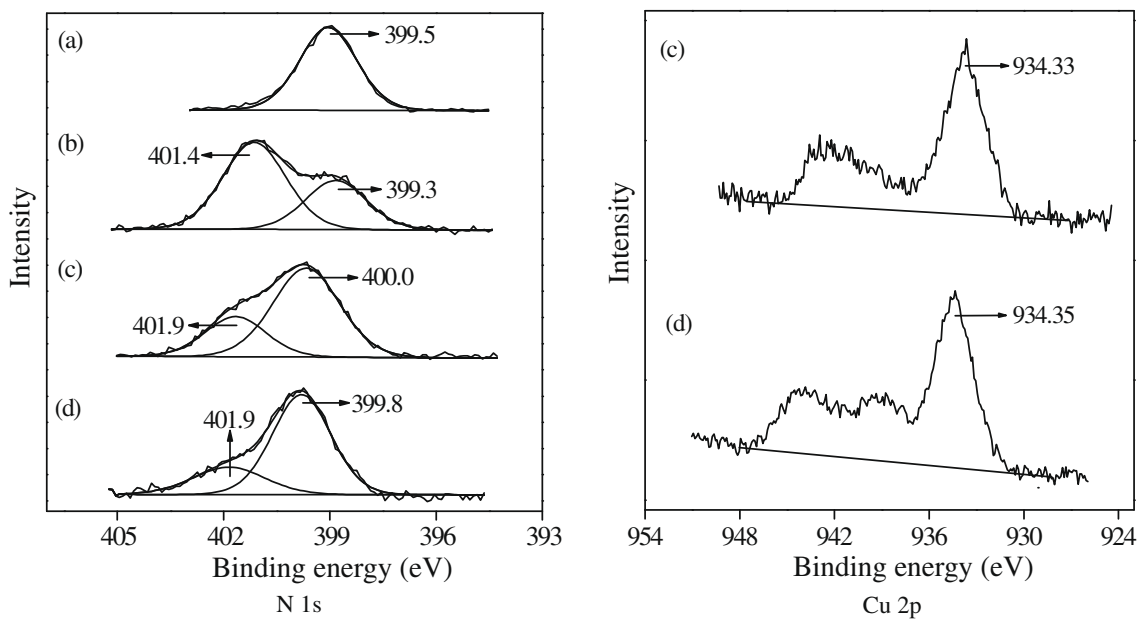

Fig. 12. XPS spectra of N 1s and Cu 2p. (a) Virgin chitosan; (b) tetracycline-loaded chitosan; (c) Cu-loaded chitosan; (d) tetracycline/Cu-loaded chitosan.

transfer from nitrogen to copper, resulting in a higher binding energy peak of $\mathrm{N} 1 \mathrm{~s}$. A similar finding was reported on the adsorption of copper onto a chitosan [28].

The binding energy of the $\mathrm{N} 1 \mathrm{~s}$ peak assigned to $-\mathrm{NH}_{2}$ and/or $\mathrm{NH}$ groups decreases in the tetracycline-loaded chitosan, while it increases significantly in $\mathrm{Cu}$ - or tetracycline/Cu-loaded chitosans. This indicates that the tetracycline adsorption mainly takes place on the sites, on which the copper is adsorbed through the coordination with the amino groups. The relative content of $-\mathrm{NH}_{3}^{+}$peak is much larger in the tetracycline-loaded chitosan than that in $\mathrm{Cu}$ or tetracycline/Cu-loaded chitosans as shown in Table 3, which may be ascribed to the generation of $-\mathrm{NH}_{3}^{+}$as a result of the interaction between tetracycline and amino groups in chitosan or the coordination of most amino groups to $\mathrm{Cu}(\mathrm{II})$.

As shown in Fig. 12, the binding energy of the copper at 934.33$934.35 \mathrm{eV}$ and the presence of a satellite band are representative of the oxidation state $(+2)$ of copper for a $\mathrm{Cu} 2 \mathrm{p}_{3 / 2}$ orbital, especially for copper sulfate (the copper salt used in this study). This indicates the existence of copper on the chitosan after the adsorption. Similar findings were reported for such copper compounds as $\mathrm{Cu}_{2} \mathrm{O}$ (932.1 eV), $\mathrm{CuO}(933.5 \mathrm{eV})$, and $\mathrm{CuSO}_{4} \cdot 5 \mathrm{H}_{2} \mathrm{O}(935.1 \mathrm{eV})[28,32]$. The binding energies are $934.89 \pm 0.3$ and $933.6 \mathrm{eV}$ for $\mathrm{CuCO}_{3}$ and $\mathrm{Cu}(\mathrm{OH})_{2}$, respectively [33]. It can be concluded that the form of copper adsorbed onto the chitosan is the same in both $\mathrm{Cu}$ - and tetracycline/Cu-loaded chitosans, and is similar to one of the following species: copper sulfate, carbonate, or hydroxide.

The above XPS analysis reveals that amino, hydroxyl, and ether groups are involved in the adsorption of tetracycline and/or copper on the chitosan, implying that tetracycline and $\mathrm{Cu}(\mathrm{II})$ would compete for these functional groups in chitosan when they coexist. This is perhaps a reason why copper sorption on chitosan decreases in the presence of tetracycline. However, the tetracycline sorption is significantly enhanced in the presence of copper. Considering that most of the amino groups are occupied by copper in the coexistence system, it can be concluded that the tetracycline adsorption mainly takes place on the sites where $\mathrm{Cu}$ (II) is adsorbed through coordination with the functional groups.

\section{Summary}

The purpose of this study was to investigate the mechanisms of the sorption involving tetracycline, copper, and chitosan. The obtained results are summarized as follows:

1. The adsorption of both tetracycline and copper can be established in $24 \mathrm{~h}$.
2. The solution pH largely affects the adsorption of tetracycline on chitosan. The tetracycline uptake increases as $\mathrm{pH}$ is increased from 2.8 to 5.6 and 2.5 to 7 in the absence and the presence of copper ion. The $\mathrm{pH}$ dependence of copper sorption behaves similarly; the sorption increases with an increase of $\mathrm{pH}$ from around 3.5-6.0.

3. The presence of copper ions significantly enhances the adsorption of tetracycline on chitosan in a wide $\mathrm{pH}$ range, probably due to the fact that the copper acts as a bridge between tetracycline and chitosan.

4. The presence of tetracycline suppresses the adsorption of copper on the chitosan, which could be ascribed to the competition of tetracycline with the functional groups in chitosan for the copper ions to form tetracycline-Cu complexes and the competition of tetracycline with copper ions for adsorptive sites at chitosan surface.

5. The adsorption isothermal data of both tetracycline and copper are well fit with the Langmuir equation. The maximum adsorption capacity and adsorption affinity constant of copper ions decrease from 1856.06 to $1486.20 \mathrm{mmol} \mathrm{kg}^{-1}$ and from 1.80 to $1.68 \mathrm{~L} \mathrm{mmol}^{-1}$ in the absence and the presence of tetracycline $\left(0.1 \mathrm{mmol} \mathrm{L}^{-1}\right)$. Both constants for tetracycline greatly increase from 53.82 to $93.04 \mathrm{mmol} \mathrm{kg}^{-1}$ and from 1.22 to $10.20 \mathrm{~L} \mathrm{mmol}^{-1}$ as the copper concentration is increased from zero to $0.5 \mathrm{mmol} \mathrm{L}^{-1}$.

6. FTIR and XPS studies show that amino, hydroxyl, and ether groups in chitosan are involved in the adsorption of tetracycline and copper on chitosan.

\section{Acknowledgments}

This work was supported by National Natural Science Foundation of China (Grant No. 5072 8806) and the foundation for Creative Research Groups of China (Grant No. 5092 1064). The fellowship to YMZ funded by Agency for Science, Technology and Research, Singapore, is appreciated (Grant No. 092101 0059).

\section{References}

[1] A.K. Sarmah, M.T. Meyer, A.B.A. Boxall, Chemosphere 65 (2006) 725-759.

[2] F.A. Nicholson, B.J. Chambers, J.R. Williams, R.J. Unwin, Bioresour. Technol. 70 (1999) 23-31.

[3] M.E. Lindsey, M. Meyer, E.M. Thurman, Anal. Chem. 73 (2001) 4640-4646.

[4] D.W. Kolpin, E.T. Furlong, M.T. Meyer, E.M. Thurman, S.D. Zaugg, L.B. Barber, H.T. Buxton, Environ. Sci. Technol. 36 (2002) 1202-1211.

[5] A.L. Batt, D.S. Aga, Anal. Chem. 77 (2005) 2940-2947. 
[6] D. Kar, P. Sur, S.K. Mandal, T. Saha, R.K. Kole, Int. J. Environ. Sci. Technol. 5 (2008) 119-124.

[7] D.R. Satapathy, P.R. Salve, Y.B. Katpatal, Environ. Geol. 56 (2009) 1323-1352.

[8] W.D. Kong, Y.G. Zhu, B.J. Fu, P. Marschner, J.Z. He, Environ. Pollut. 143 (2006) 129-137.

[9] D.A. Jia, D.M. Zhou, Y.J. Wang, H.W. Zhu, J.L. Chen, Geoderma 146 (2008) 224 230.

[10] Y.J. Wang, D.A. Jia, R.J. Sun, H.W. Zhu, D.M. Zhou, Environ. Sci. Technol. 42 (2008) 3254-3259.

[11] S. Babel, T.A. Kurniawan, J. Hazard. Mater. 97 (2003) 219-243.

[12] M.Y. Chang, R.S. Juang, J. Colloid Interf. Sci. 278 (2004) 18-25.

[13] I. Uzun, F. Gel, J. Colloid Interf. Sci. 274 (2004) 398-412.

[14] J.C.Y. Ng, W.H. Cheung, G. McKay, J. Colloid Interf. Sci. 255 (2002) 64-74.

[15] S.T. Lee, F.L. Mi, Y.J. Shen, S.S. Shyu, Polymer 42 (2001) 879-1892.

[16] R.A. Figueroa, A. Leonard, A.A. Mackay, Environ. Sci. Technol. 38 (2004) 476 483.

17] J.P. Chen, M.L. Chua, B.P. Zhang, Waste Manage. 22 (2002) 711-719.

[18] J.P. Chen, L. Wang, Sep. Sci. Technol. 36 (2001) 3617-3637.

[19] L. Yang, J.P. Chen, Bioresour. Technol. 99 (2008) 297-307.

[20] W.D. Schecher, MINEQL+: A Chemical Equilibrium Program for Personal Computers, User Manual, Version 4.5, Environmental Research Software, Hallowell, ME, 2002.
[21] D.M. Zhou, Y.J. Wang, L. Cang, X.Z. Hao, X.S. Luo, Chemosphere 57 (2004) 1237-1244.

[22] A.A. MacKay, B. Canterbury, J. Environ. Qual. 34 (2005) 1964-1971.

[23] J.P. Chen, L. Wang, S.W. Zou, Chem. Eng. J. 131 (2007) 209-215.

[24] W.S.W. Ngah, C.S. Endud, R. Mayanar, React. Funct. Polym. 50 (2002) 181-190.

[25] M. Malandrino, O. Abollino, A. Giacomino, M. Aceto, E. Mentasti, J. Colloid Interf. Sci. 299 (2006) 537-546.

[26] O. Abollino, A. Giacomino, M. Malandrino, E. Mentasti, Appl. Clay Sci. 38 (2008) 227-236.

[27] G. Lawrie, I. Keen, B. Drew, A. Chandler-Temple, L. Rintoul, P. Fredericks, L. Grondahl, Biomacromolecules 8 (2007) 2533-2541.

[28] L. Dambies, C. Guimon, S. Yiacoumi, E. Guibal, Colloids Surf. A 177 (2001) 203214.

[29] A.G. Karakecili, C. Satriano, M. Gumusdereliioglu, G. Marletta, J. Appl. Polym. Sci. 106 (2007) 3884-3888.

[30] S.F. Lim, Y.M. Zheng, S.W. Zou, J.P. Chen, Environ. Sci. Technol. 42 (2008) 25512556.

[31] J.P. Chen, L. Yang, Langmuir 22 (2006) 8906-8914.

[32] C.D. Wagner, W.M. Riggs, L.E. Davis, J.F. Moulder, Handbook of X-ray Photoelectron Spectroscopy, Perkin Elmer Corporation, 1979.

[33] S.H. Park, S. McClain, Z.R. Tian, S.L. Suib, C. Karwacki, Chem. Mater. 9 (1997) 176-183. 